\title{
THINKING FASCISM
}





\section{THINKING FASCISM}

Sapphic Modernism and Fascist Modernity

\section{ERIN G. CARLSTON}


Stanford University Press

Stanford, California

(C) 1998 by the Board of Trustees of the

Leland Stanford Junior University

Printed in the United States of America

CIP data appear at the end of the book 
In memory of my sister

Catherine Alice Carlston Brisbois (Kim Eun Sook) 
